\title{
Cambios microscópicos en ganglios linfáticos de ratones inoculados con veneno de Bothrops alternatus
}

\author{
Echeverría, S.M. ${ }^{1}$; Teibler, G.P.'; Maruñak, S.L. ${ }^{2}$; Lértora, W.J. ${ }^{3}$; Leiva, L.C. ${ }^{1}$ \\ ${ }^{1}$ Laboratorio de Investigación en Proteínas (LabInPro), Fac.Cs.Exactas, Universidad Nacional del Nordeste \\ (UNNE). Av.Libertad 5470, Corrientes (3400), Argentina. ${ }^{2}$ Cátedra Farmacología, ${ }^{3}$ Cátedra Patología General, \\ Fac.Cs.Veterinarias UNNE. E-mail: silvinaecheverria@hotmail.com
}

\begin{abstract}
Resumen
Echeverría, S.M.; Teibler, G.P.; Maruñak, S.L.; Lértora, W.J.; Leiva, L.C.: Cambios microscópicos en ganglios linfáticos de ratones inoculados con veneno de Bothrops alternatus. Rev. vet. 26: 2, 113-119, 2015. En la intoxicación por veneno de Bothrops alternatus han sido bien estudiados el músculo estriado, riñón y sistema vascular; pero poco se conocen los cambios a nivel de los órganos linfoides secundarios. Se presenta un estudio histológico de los ganglios linfáticos inguinales y poplíteos, a fin de distinguir el impacto fisiopatológico que desencadena este veneno. Se utilizaron ratones albinos machos de la cepa CF-1, los cuales fueron inoculados con diferentes dosis de veneno (1, 10 y 20 ug por ratón, vía s.c.) a diferentes tiempos de exposición (24, 48, 72 y $96 \mathrm{~h}$ ) para el estudio en ganglios inguinales. En los poplíteos se ensayó la dosis 20 ug (vía i.m.) a los tiempos 6, 12, 24 y $72 \mathrm{~h}$. Todos los ganglios fueron removidos y procesados por técnica histológica clásica H\&E. Se detectaron cambios histológicos tempranos en los ganglios poplíteos $(6 \mathrm{~h})$ e inguinales $(24 \mathrm{~h})$, caracterizados por dilatación y congestión de espacios subcapsulares y aumento en la migración linfocitaria a través de las vénulas del endotelio alto en la paracorteza. También se observaron cambios reactivos, reconociéndose una hiperplasia a expensas de la región de células T. A pesar de que los cambios aparecieron más precozmente en los ganglios poplíteos, no se detectaron diferencias entre éstos y los inguinales, aún cuando la vía de inoculación fue diferente. Estos hallazgos preliminares ponen en evidencia que la intoxicación inducida por el veneno, además de los efectos tisulares locales conocidos, compromete al sistema inmune innato y adaptativo. Las evidencias reunidas a nivel de ganglios linfáticos, muy poco estudiados hasta el presente en la toxicología ofídica, generan un novel conocimiento en el inicio de la respuesta inmune adaptativa durante la intoxicación.
\end{abstract}

Palabras clave: ratón, ganglios linfáticos, veneno, Bothrops alternatus, cambios histológi$\cos$.

\begin{abstract}
Echeverría, S.M.; Teibler, G.P.; Maruñak, S.L.; Lértora, W.J.; Leiva, L.C.: Histological changes in lymphatic nodes of mice inoculated with venom of Bothrops alternatus. Rev. vet. 26: 2, 113-119, 2015. In the past, Bothrops alternatus envenoming was widely studied in many organs of mice. However, little is known about the alterations in secondary lymphoid organs. In this paper we present a preliminary histological study of the early events that occur in inguinal and popliteal lymph nodes in order to determine the pathophysiological effects that $B$. alternatus venom triggers in key organs of the immune system. The assay was carried out in inguinal lymph nodes of mice (male CF-1) inoculated i.v. with different doses of venom (1, 10 and $20 \mathrm{ug}$ ) at 24, 48, 72 and $96 \mathrm{~h}$; another assay was also carried out in popliteal lymph nodes using i.m. injections of 20 ug crude venom at $6,12,24$ and $72 \mathrm{~h}$. All of the lymphoid nodes were processed according to classical techniques (H\&E). The assessment of morphological changes was performed by microscopic examination of non-serial section cuts. In all of the cases nodes showed a cellular response without compromising tissue integrity. Early histological changes in the popliteal (6 h) and inguinal $(24 \mathrm{~h})$ lymph nodes were detected, characterized by subcapsular space dilatation, congestion and increase of lymphocyte migration via the high endothelial venules of the paracortex. Reactive changes were also observed in this area, with hyperplasia regardless the $\mathrm{T}$ cell region. No differences
\end{abstract}




\begin{abstract}
were detected between inguinal and popliteal lymph nodes, even for different inoculation routes. These preliminary findings highlight the deletereous effects in innate and adaptive immune system caused by $B$. alternatus venom besides the local tissue effects reported in previous works. Such findings in the secondary lymphoid organs contribute with updated knowledge regarding the adaptive immune responses that take place at the early stages of $B$. alternatus envenoming.
\end{abstract}

Key words: mice, lymph node, venom, Bothrops alternatus, histological changes.

\section{INTRODUCCIÓN}

En el nordeste argentino la mayoría de las intoxicaciones ofídicas son causadas por serpientes del género Bothrops, entre ellas Bothrops alternatus, una de las más abundantes ${ }^{2}$, conocida vulgarmente como yarará grande o víbora de la cruz ${ }^{3}$.

El accidente botrópico causado por su mordedura se caracteriza por efectos locales que se presentan minutos después de la inyección del veneno e incluyen con frecuencia dolor intenso e inmediato, edema y hemorragia local, con aparición precoz y de carácter progresivo durante las primeras $6 \mathrm{~h}$. Tales signos son seguidos en muchos casos por aumento de tamaño de ganglios linfáticos, ampollas y necrosis del área que rodea al sitio de la mordedura, que pueden aparecer de forma tardía luego de $12 \mathrm{~h}$ de ocurrida la mordedura ${ }^{11}$.

Tal secuencia, que puede evolucionar desde una inflamación aguda hasta una destrucción masiva de tejido, implica eventos celulares y moleculares que ocurren desde la penetración del veneno hasta el desarrollo, evolución y resolución de la lesión que, en general, son poco conocidos ${ }^{12}$.

Numerosos trabajos describen los eventos inflamatorios por mordeduras ocasionadas por especies botrópicas, específicamente los relacionados a los cambios morfológicos producidos en diversos órganos, con énfasis en aquellos que son blancos de las toxinas del veneno $4,5,7,8,10,12,13$. Los órganos y tejidos más estudiados en el cuadro de esta intoxicación son el músculo estriado, el riñón y el sistema vascular, sin embargo poco se sabe de los cambios que ocurren a nivel de los ganglios linfáticos regionales. Se desconoce la cronodinamia ocurrida desde la respuesta innata que caracteriza al proceso inflamatorio hasta la respuesta adaptativa definida por la producción de inmunoglobulinas en órganos linfoides secundarios. Sobre este aspecto es de interés abordar inicialmente el conocimiento sobre la reacción del ganglio, órgano vital para la respuesta inmune, frente a la invasión de las toxinas del veneno.

Existen estudios que evaluaron la acción de fracciones como la crotoxina y la fosfolipasa $\mathrm{A}_{2}$ del veneno de Crotalus durissus terrificus en ganglios mesentéricos de ratas ${ }^{14}$, sin embargo, dada la fisiopatología distintiva del veneno crotálico, del tipo neurotóxico y no hemorrágico, tales hallazgos no son transferibles a la intoxicación botrópica.
El objetivo de este trabajo fue describir los cambios histológicos tempranos en ganglios linfáticos de ratones inoculados con veneno de $B$. alternatus, a fin de determinar el impacto fisiopatológico sobre los tejidos linfoides, claves para el inicio de la respuesta inmune adaptativa.

\section{MATERIAL Y MÉTODOS}

Veneno. Se trabajó con mezclas de venenos desecados de especimenes adultos de B. alternatus del nordeste argentino mantenidos en cautiverio en el Serpentario de la Ciudad de Corrientes (CEPSAN), Argentina. Las mismas fueron homogeneizadas y conservadas a $-20^{\circ} \mathrm{C}$. El veneno se disolvió en buffer fosfato pH 7,2 (PBS) en el momento de uso. El material insoluble se separó por centrifugación, obteniéndose un sobrenadante límpido que se destinó a los ensayos.

Animales. Se utilizaron ratones albinos machos de la cepa CF1 con pesos corporales de 18 a 20 g. Los animales fueron alimentados con dieta balanceada y acceso constante al agua. La temperatura del bioterio fue de $23 \pm 2^{\circ} \mathrm{C}$ y la humedad relativa entre 35 y $65 \%$. Los procedimientos de este estudio fueron aprobados por el Comité de Ética y Bioseguridad de la Facultad de Ciencias Veterinarias de la UNNE, protocolo $\mathrm{N}^{\mathrm{o}} 056$.

Estudio histológico de ganglios linfáticos inguinales. Se estudió el efecto de diferentes dosis de veneno (1, 10 y 20 ug por ratón) a diferentes tiempos de exposición (24, 48, 72 y $96 \mathrm{~h})$. Para ello se emplearon tres grupos de ratones (un grupo para cada dosis) de 12 individuos cada uno, destinándose 3 animales para cada tiempo de exposición. Un cuarto grupo de 12 ratones ( $\mathrm{n}=3$ para cada tiempo de exposición) se empleó como control. Los ratones fueron inoculados por vía subcutánea en la almohadilla plantar derecha con $0,05 \mathrm{ml}$ de veneno de $B$. alternatus $(400 ; 200$ y $100 \mathrm{ug} / \mathrm{ml})$ en solución tamponada de fosfatos (PBS, $\mathrm{pH} 7,2$ ). Los ratones control fueron inoculados con buffer de fosfatos $\mathrm{pH} 7,2$. Luego de 24, 48, 72 y 96 h de exposición a cada una de las dosis de veneno, los ratones fueron sacrificados y se extrajeron los ganglios linfáticos inguinales post observación de la piel de esta zona. Las muestras se fijaron en solución de formaldehido bufferado al $10 \%$ por 12 horas, luego fueron procesadas según la técnica 
histológica clásica para bloques parafinados y cortadas en micrótomo tipo Minot en secciones de $4 \mu \mathrm{m}$, coloreándose con hematoxilina y eosina (H\&E). Los ganglios controles fueron procesados de idéntica manera. Se procedió a la observación microscópica de los cortes para la evaluación de los cambios morfológicos. Se evaluó la dilatación del seno subcapsular, la presencia de eritrocitos en los mismos y la circulación de linfocitos a través de las vénulas del endotelio alto (VEA) ${ }^{6}$ paracorticales. Se analizaron quince a veinte vénulas de cortes no seriados de tres animales por grupo.

Estudio histológico de ganglios linfáticos poplíteos. Se ensayó sólo la dosis más alta (20 ug), por considerarla aquélla que induce cambios manifiestos en el tejido linfoide. Para ello se trabajó con dos grupos de animales, uno de ellos destinado a control. Se inocularon 3 ratones por grupo horario, con $0,05 \mathrm{ml} \mathrm{de}$ solución de veneno $(400 \mu \mathrm{g} / \mathrm{ml}$ de $\mathrm{PBS} \mathrm{pH} 7,2)$ vía $i . m$. en músculo gastrocnemio derecho. Los ratones control fueron inoculados vía i.m. con buffer de fosfatos $\mathrm{pH}$ 7,2. Luego de 6, 12, 24 y 72 horas los ratones fueron sacrificados y tras la observación del área afectada se extrajeron los ganglios poplíteos junto con los músculos. Se realizó el procesamiento histológico descrito anteriormente y los cortes coloreados con H\&E se sometieron a observación microscópica para evaluación de los cambios inducidos por el veneno.

\section{RESULTADOS}

Ganglios inguinales. Teniendo en cuenta que las dosis ensayadas fueron subletales, todos los animales sobrevivieron al ensayo hasta el tiempo de sacrificio. La observación macroscópica de la piel adyacente a los ganglios inguinales evidenció una zona con extensa hemorragia en todas las dosis de veneno ensayadas, siendo más acentuada a las concentraciones más altas, y decreció con el transcurso del tiempo.

El análisis histopatológico mostró, mediante la microscopía óptica, cambios morfológicos bajo un comportamiento dosis-dependiente. La estructura general de estos órganos se presentó conservada, se detectaron diferencias con respecto al control, que fueron mínimas a la dosis de $1 \mathrm{ug}$, y más acentuadas con la inoculación de 20 ug/ratón. Dado que los cambios detectados fueron de naturaleza similar en las distintas dosis ensayadas, solo se describirán los registrados en ratones inoculados con la mayor dosis, según el tiempo transcurrido desde la inoculación.

A las 24 horas post inoculación del veneno los senos supcapsulares se presentaron dilatados, con gran cantidad de hematíes. La presencia de glóbulos rojos se redujo progresivamente en los 3 días subsiguientes, en tanto que el espacio subcapsular solo disminuyó al segundo día y conservó sus dimensiones por el resto del tiempo que duró el estudio (Tabla 1 y Figura 1).

La zona cortical mostró una imagen comparable al control, con 1 o 2 folículos secundarios (zona de cé-
Tabla 1. Cambios histológicos del seno subcapsular de ganglios inguinales (dosis: $20 \mu \mathrm{g}$ de veneno).

\begin{tabular}{ccc}
\hline $\begin{array}{c}\text { tiempo de } \\
\text { exposición }\end{array}$ & dilatación* & $\begin{array}{c}\text { presencia de } \\
\text { hematíes** }\end{array}$ \\
\hline control & $(-)$ & ausentes \\
$24 \mathrm{~h}$ & $(+++)$ & abundantes \\
$48 \mathrm{~h}$ & $(++)$ & regulares \\
$72 \mathrm{~h}$ & $(++)$ & escasos \\
$96 \mathrm{~h}$ & $(++)$ & escasos \\
\hline
\end{tabular}

$*(-)<5$ um, $(+) 5-15$ um, $(++) 15-25$ um, $(+++)>25$ um. **ausente: 0 hematíes/100 um² ${ }^{2}$, escaso: 1-3 hematíes/100 $u^{2}$, regular: $4-5$ hematíes $/ 100 \mathrm{um}^{2}$, abundante: $>5$ hematíes $/ 100 \mathrm{um}^{2}$.

Tabla 2. Cambios histológicos del seno subcapsular de ganglios poplíteos (dosis: 20 ug de veneno).

\begin{tabular}{ccc}
\hline $\begin{array}{c}\text { tiempo de } \\
\text { exposición }\end{array}$ & dilatación* & $\begin{array}{c}\text { presencia de } \\
\text { hematíes** }^{*}\end{array}$ \\
\hline $\begin{array}{c}\text { control } \\
6 \mathrm{~h}\end{array}$ & $(-)$ & ausentes \\
$12 \mathrm{~h}$ & $(+++)$ & abundantes \\
$24 \mathrm{~h}$ & $(+++)$ & abundantes \\
$72 \mathrm{~h}$ & $(+++)$ & escasos \\
\hline
\end{tabular}

$*(-)<5$ um, $(+) 5-15$ um, $(++) 15-25$ um, $(+++)>25$ um **ausente: 0 hematíes/100 um ${ }^{2}$, escaso: $1-3$ hematíes/100 $\mathrm{um}^{2}$, regular: 4-5 hematíes $/ 100 \mathrm{um}^{2}$, abundante: $>5$ hematíes $/ 100 \mathrm{um}^{2}$.

lulas B), al primer día de evaluación. A las $48 \mathrm{~h}$ post inoculación del veneno se presentó un incremento de células a expensas de los linfocitos T que se encuentran principalmente debajo y más centralmente a los folículos, en las cuerdas paracorticales (paracorteza o corteza profunda), que desde ahora denominaremos "zona T", acrecentándose así el manto celular alrededor de la zona interfolicular (Figura 1, C y D).

Al tercer día se observó una hiperplasia de células $\mathrm{T}$, que llegó a cubrir las células B del área folicular. Con el transcurso del tiempo se acentuó este fenómeno, detectándose a las $96 \mathrm{~h}$ cambios proliferativos con aparición de pequeños centros germinales en la zona folicular más externa, cercana a la cápsula (Figura 1,G).

En la zona paracortical de los ganglios inguinales tratados se detectó un aumento en la circulación linfocitaria a través de las VEA, tanto de células en la luz vascular como en migración desde el vaso hacia el parénquima ganglionar, a través del endotelio (Figura 2). Si bien estos cambios se observaron a las $24 \mathrm{~h}$, la mayor celularidad se detectó a las 48 h (Figura 3.A).

Ganglios poplíteos. El estudio de la acción del veneno sobre estos ganglios, que son los primeros en el drenaje de fluidos linfáticos cercanos al músculo gastrocnemio, evidenció en la observación macroscópica, una zona hemorrágica que comprometió al tejido ganglionar y se extendió a la piel circundante de la zona abdominal. No obstante, los cortes histológicos mos- 

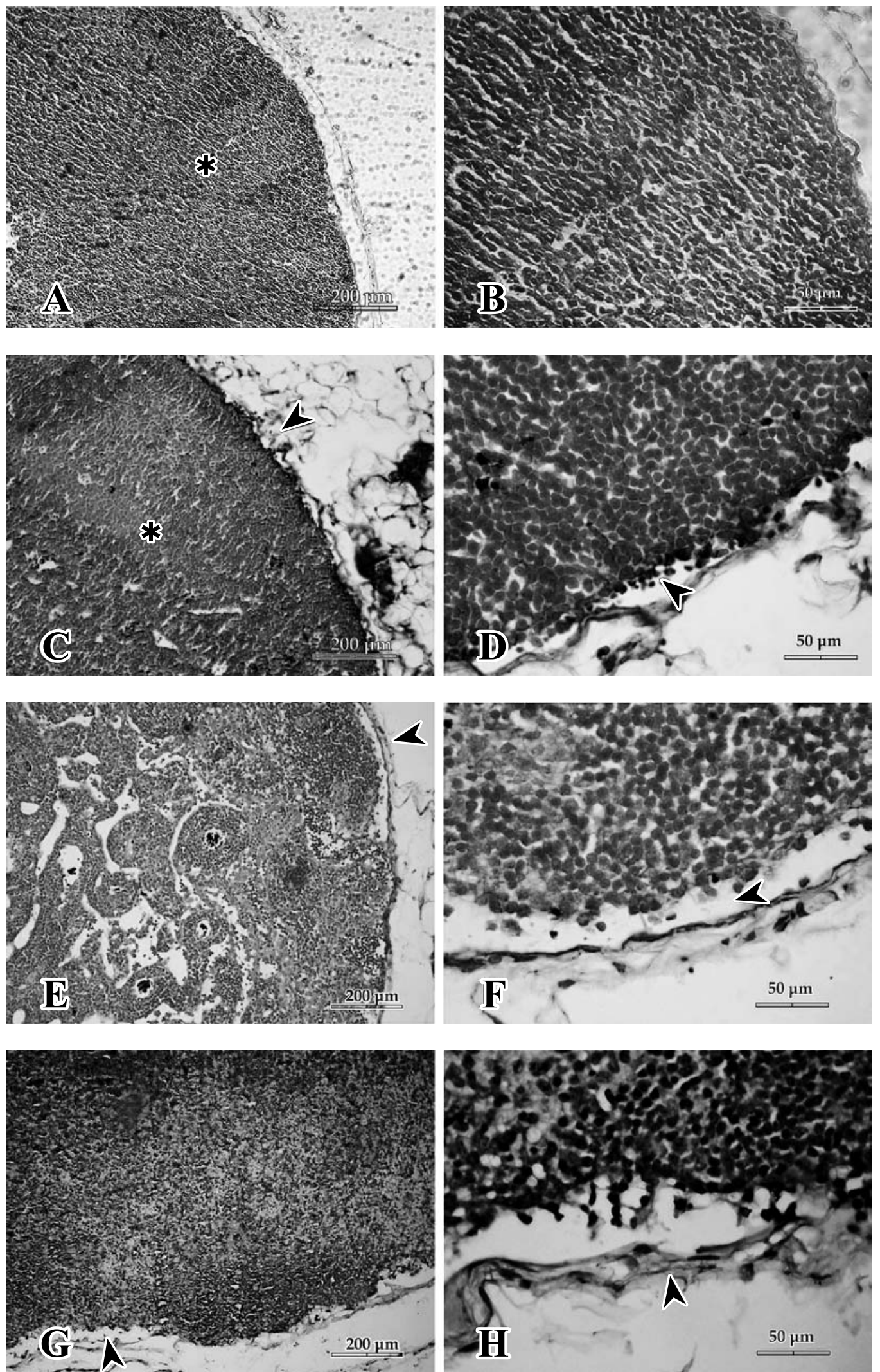

Figura 1. Análisis histopatológico de ganglios inguinales, a diferentes tiempos de exposición, inoculados con 20 ug de veneno (H\&E). A. Control (* folículo secundario). B. Control, zona de corteza y espacio subcapsular. C. Espacio subcapsular dilatado con hematíes (>), folículo linfático secundario y región interfolicular hiperplásica (*). D. Espacio subcapsular dilatado con abundante presencia de hematíes (૪). E. Espacio subcapsular dilatado (>). F. Espacio subcapsular dilatado con escasos hematíes (>). G. Espacio subcapsular levemente dilatado (૪); expansión celular de la zona T en el área folicular de la corteza. H. Dilatación del espacio subcapsular (૪). 

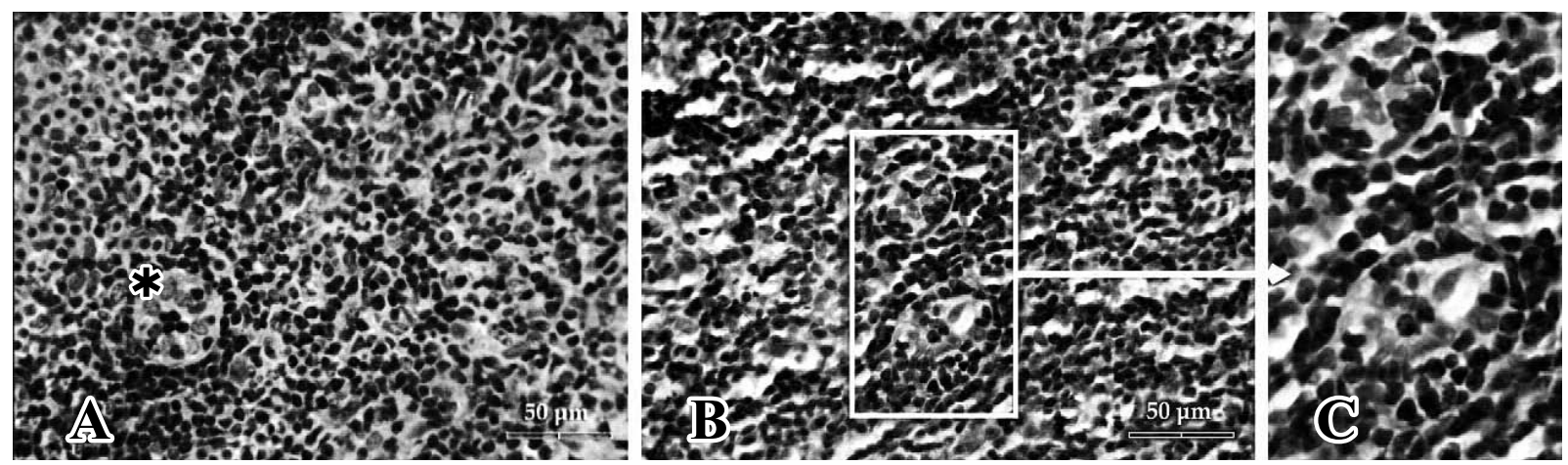

Figura 2. Análisis histopatológico de zona paracortical de ganglios inguinales de ratón tratado con $20 \mu \mathrm{g}$ de veneno (48 h). Tinción: H\&E. A. VEA (*) en ratón control. B. VEA con gran celularidad (recuadro). C. Aumento de la zona de las VEA, donde pueden observarse linfocitos atravesando la pared del endotelio.
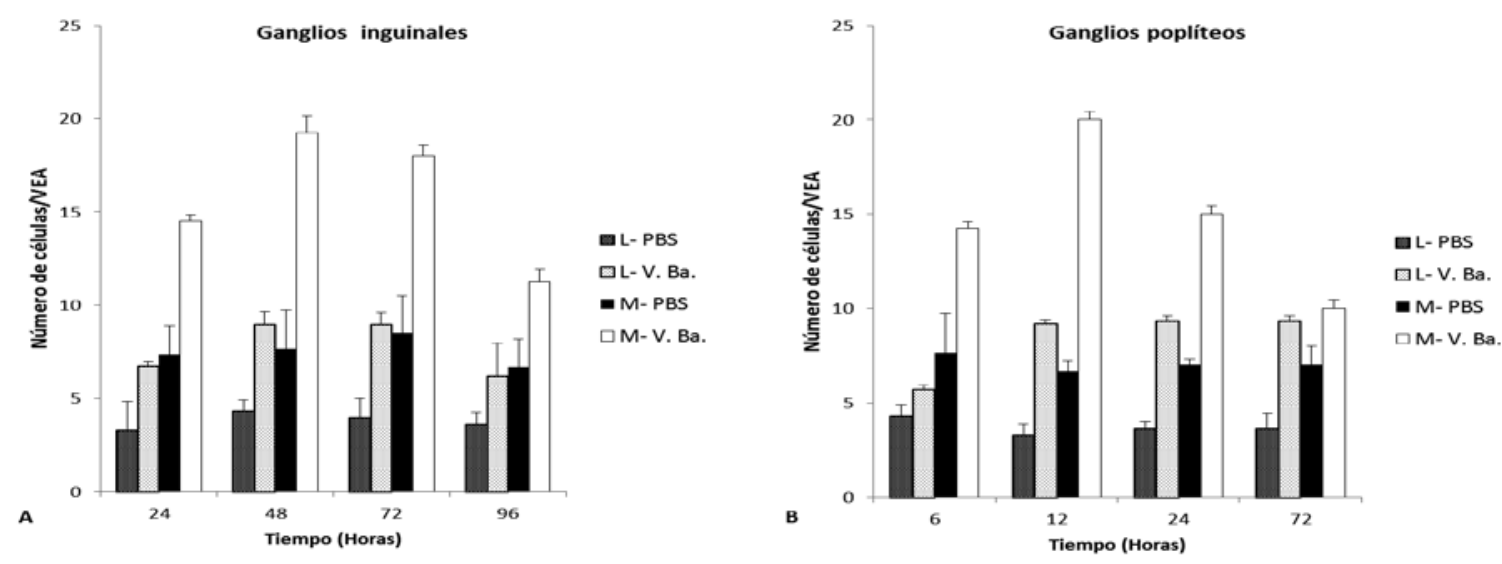

Figura 3. Efecto del veneno sobre la circulación linfocitaria a través de las vénulas endotelio alto (VEA) en nódulos linfáticos inguinales (A) y poplíteos (B). La cantidad de linfocitos se determinó tanto en la luz vascular (L) como en migración a través del endotelio (M).
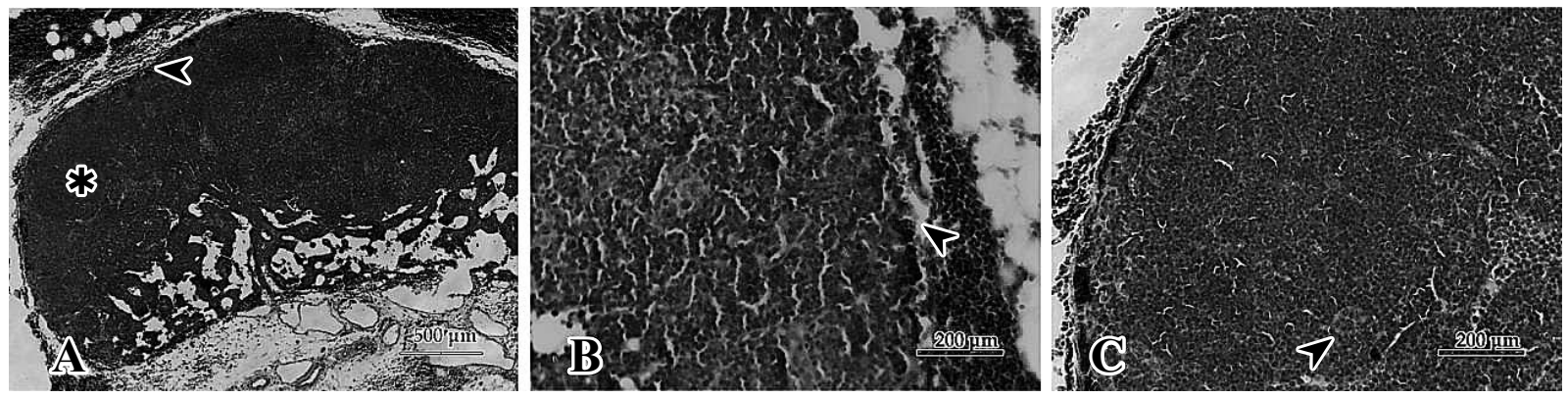

Figura 4. Ganglio poplíteo de ratón tratado con 20 ug de veneno (12 h). Tinción H\&E. A. Espacio subcapsular dilatado y congestivo (૪). Área folicular con hiperplasia de zona T $(\boldsymbol{*})$. B. Espacio subcapsular dilatado con abundante presencia de hematíes (\). C. VEA con células en la luz, nótense linfocitos atravesando la pared del endotelio (>).

traron que la estructura del ganglio permanecía conservada a pesar de la marcada hemorragia que presentó el área muscular circundante.

A las 6 horas de la inoculación los nódulos ya mostraban dilatación del espacio subcapsular, con abundantes hematíes, fenómeno que persistió durante las $6 \mathrm{~h}$ subsiguientes disminuyendo a partir de las $24 \mathrm{~h}$, mientras que en el seno subcapsular se redujo recién a partir de las $72 \mathrm{~h}$ (Tabla 2).

A las $6 \mathrm{~h}$ los cambios en la zona folicular se caracterizaron por expansión del área interfolicular. Luego, a las $24 \mathrm{~h}$ se detectó hiperplasia a expensas de la zona $\mathrm{T}$ que no permite diferenciar los folículos (zona de células zonas B) que se ubican en la corteza.

Las VEA de la zona paracortical revelaron linfocitos en la luz vascular, poniendo en evidencia el aumento de la circulación de estas células desde la sangre hacia el parénquima (Figura 4). Si bien estos cambios se observaron a las $6 \mathrm{~h}$, la mayor migración se detectó a las $12 \mathrm{~h}$ (Figura 3.B), mientras que la celularidad en la luz vascular se mantuvo elevada durante los 3 días que duró el estudio. 


\section{DISCUSIÓN}

Los estudios a nivel de ganglios linfáticos mostraron una respuesta celular ante la inoculación del veneno de $B$. alternatus, sin compromiso de la integridad tisular. Tanto los ganglios inguinales como poplíteos reaccionaron de modo similar, aún cuando la vía de inoculación fue diferente, subcutánea e intramuscular respectivamente. Sin embargo la aparición de los eventos fue más temprana en los ganglios poplíteos, probablemente por la cercanía del nódulo al punto de inoculación.

Los eventos descriptos en las primeras horas para los ganglios poplíteos, y primeros días para los inguinales, se caracterizaron por cambios reactivos que se produjeron a partir de las células $\mathrm{T}$, las que situadas en la paracorteza iniciaron una expansión hacia la zona folicular de la corteza, tornando menos notorios los folículos de células B. Esta hiperplasia celular T está descripta en aquellos eventos tales como reacciones inmunitarias inducidas por fármacos como la difenilhidantoína (Dilantin), infecciones virales agudas, mononucleosis infecciosa y después de las vacunaciones contra algunas enfermedades virales ${ }^{9}$.

El aumento de la celularidad y los cambios observados hacia las $96 \mathrm{~h}$ en el área folicular de la corteza, denotarían la reactividad del ganglio dando inicio a la respuesta inmune adaptativa con pequeños centros germinativos. A nivel de corteza profunda se observó que las VEA mostraron un aumento en el número de linfocitos, tanto en la luz como en migración a través de las células del endotelio vascular, que se sostuvo aún a las $48 \mathrm{~h}$, disminuyendo a partir de las $72 \mathrm{~h}$. En los ganglios poplíteos este proceso se presentó de modo más temprano, con un máximo a las $12 \mathrm{~h}$.

Estos resultados no concuerdan con estudios anteriores donde, al aplicar la fracción crotoxina (con su fosfolipasa $\mathrm{A}_{2}$ ) del veneno de Crotalus durissus terrificus en ganglios mesentéricos de ratas, obtuvieron un aumento temprano del número de células (linfocitos $\mathrm{T}$ y linfocitos B), tan solo una hora después de tratamiento, sin detectar diferencias en la celularidad a nivel de las VEA a partir de las $4 \mathrm{~h}^{14}$. Por el contrario, los resultados obtenidos con veneno de $B$. alternatus muestran una acción más prolongada a este nivel y una reactividad que se extiende a todo el ganglio linfático.

Estas diferencias pueden explicarse teniendo en cuenta que el veneno crotálico tiene un comportamiento no inflamatorio cuyo principal componente, la crotoxina, posee una reconocida acción inhibitoria de respuesta inmune humoral clásica ante antígenos proteicos ${ }^{1}$. En cambio, el veneno botrópico reúne toxinas proinflamatorias capaces de activar la respuesta inmune temprana, que llega a visualizarse -tal como se muestra en este trabajo- en nódulos linfoides morfológicamente reactivos.

En conclusión, los resultados aquí obtenidos reflejan la reactividad del ganglio linfático ante la presencia de las toxinas del veneno, contra las cuales moviliza linfocitos para la consecuente respuesta inmunológica. Estos hallazgos preliminares, en nódulos linfáticos de ratón, evidencian que la intoxicación inducida por el veneno, además de los efectos tisulares locales conocidos, compromete al sistema inmune innato y adaptativo. Las evidencias reunidas a nivel de órganos linfoides secundarios, muy poco estudiados hasta el presente en la toxicología ofídica, generan un novel conocimiento en el inicio de la respuesta inmune adaptativa durante la intoxicación.

Agradecimientos. A la Lic. Laura Rey, Directora del CEPSAN, por brindarnos el veneno utilizado. A la Agencia Nacional de Promoción Científica y Técnica por la ayuda económica brindada (Proyecto PRH 2007 $\mathrm{N}^{\circ} 35$ ). A la Dra. Emila García Denegri por su colaboración técnica.

\section{REFERENCIAS}

1. Cardoso DF, Mota I. 1997. Effect of Crotalus venom on the humoral and cellular immune response. Toxicon 35: 607-612.

2. Duméril AM, Bibron G, Dumeril AH. 1854. Erpétologie générale ou histoire naturelle complète des reptiles, Librairie Encyclopédique Roret, París, 1536 p.

3. Esteso SC. 1985. Ofidismo en la República Argentina, Ed. Arpón, Córdoba, p. 59-71.

4. Farsky SH, Walber Y, Costa-Cruz M, Curry Y, Texeira CF. 1997. Leukocyte response induced by Bothrops jararaca crude venom: In vivo and in vitro studies. Toxicon 35 : 185-193.

5. Furtado MF, Maruyama M, Kamiguti AS, Antonio LC. 1991. Comparative study of nine Bothrops snake venoms from adult female snakes and their offspring. Toxicon 29 : 219-226.

6. Girard JP, Springer TA. 1995. High endothelial venules (HEVs): specialized endothelium for lymphocyte migration. Inmunol today 16: 449-457.

7. Gutiérrez JM, Escalante T, Rucavado A. 2009. Experimental pathophysiology of systemic alterations induced by Bothrops asper snake venom. Toxicon 54: 976-987.

8. Gutiérrez JM, Rucavado A, Chaves F, Diaz C, Escalante T. 2009. Experimental pathology of local tissue damage induced by Bothrops asper snake venom. Toxicon 54: 958975.

9. Kumar V, Abbas AK, Fausto N, Aster JC. 2010. Robbins y Cotran-Patología estructural y funcional, $8^{\circ}$ ed., Elsevier, Amsterdam, $1464 \mathrm{p}$.

10. Mora J, Mora R, Lomonte B, Gutierrez JM. 2008. Effects of Bothrops asper snake venom on lymphatic vessels: insights in to a hidden aspect of envenomation. PLoS Negl Trop Dis 2, 318.

11. Navarrete MB, Silva WH, Vargas A. 2010. The poisonous snakes of public health importance of Peru. RedVet 11. www.veterinaria.org/revistas/redvet/n070710.html

12. Teixeira C, Cury Y, Moreira V, Picolo G, Chaves F. 2009. Inflammation induced by Bothrops asper venom. Toxicon 54: 67-76. 
13. Wanderley CW, Silva CM, Wong DV et al. 2014. Bothrops jararacussu snake venom-induces a local inflammatory response in a prostanoid- and neutrophil-dependent manner. Toxicon 90: 134-147.

14. Zambelli VO, Sampaio SC, Sudo LS et al. 2008. Crotoxin alters lymphocyte distribution in rats: Involvement of adhesion molecules and lipoxygenase-derived mediators. Toxicon 51: 1357-1367.

\section{Revista Veterinaria ingresa a SciELO}

Revista Veterinaria, publicación oficial de la Facultad de Ciencias Veterinarias de la Universidad Nacional del Nordeste (Corrientes, Argentina), ha logrado acceder al Núcleo Básico de Revistas Científicas Argentinas (Nivel 1), luego de calificar adecuadamente en el Centro Argentino de Información Científica y Tecnológica (CAICYT), según Resolución 2485/14 del Consejo Nacional de Investigaciones Científicas y Técnicas (CONICET).

Sobre un puntaje máximo de 33 se obtuvieron 32 puntos. Tal calificación constituye "una garantía de la excelencia de la publicación" (sic) y queda expedita la vía del Portal SciELO (Scientific Electronic Library Online) para los artículos publicados.

En tal calificación gravitó positivamente la circunstancia de haber aumentado el índice de impacto (Scimago-Elsevier) y haber disminuido las autocitaciones. También se tuvieron en cuenta aspectos como la amplia cobertura de la revista, la calidad científica del Comité Editorial, los criterios de evaluación de los artículos, el origen de los autores (locales $60 \%$, nacionales $13 \%$, extranjeros $26 \%$, en idioma inglés), el adecuado balance entre trabajos científicos originales y reseñas bibliográficas (ambos con alta calidad), así como el estricto cumplimiento de la periodicidad semestral y la favorable acogida por indizadores como Cab, Doaj, Ebsco, Gale Cengage, Infocyt, Latindex y Scopus.

Se consolida de esta manera la continuidad de "Revista Veterinaria", que en el año próximo (2015) cumplirá 50 años de existencia, en coincidencia con el $95^{\circ}$ aniversario de la creación de la Facultad. 